\title{
Classification of Childhood Glaucoma in Patients of a Government Tertiary Hospital in Manila, Philippines using the Childhood Glaucoma Research Network System
}

\author{
Martin Joseph B. Babaran, MD and Nilo Vincent DG. FlorCruz, MD \\ Department of Ophthalmology and Visual Sciences, Philippine General Hospital, University of the Philippines Manila
}

\begin{abstract}
Background. Childhood glaucoma is a rare multifactorial disease with limited information regarding the demographics and characteristics in the Filipino setting. It can be categorized via the Childhood Glaucoma Research Network Classification scheme.

Objective. Determine the clinical classification of patients diagnosed with childhood glaucoma in the ophthalmology service of a government tertiary hospital in Manila, Philippines.

Methods. Medical records of all patients $\leq 16$ years-old referred to Glaucoma Section of Philippine General Hospital from January 2015 to December 2017 were reviewed retrospectively and classified.

Results. One-hundred four (104) eyes in 77 children were classified. Glaucoma associated with acquired conditions was the most prevalent in $44.2 \%$ of the patients with trauma consisting of $19.5 \%$ of all patients. Primary childhood glaucoma consisted of $15.6 \%$ and juvenile open-angle glaucoma was diagnosed in $5.2 \%$. Glaucoma following cataract surgery was noted in $7.8 \%$ of patients. Trabeculectomy was the primary surgical intervention in $22.2 \%$ of eyes, with $78.9 \%$ of eyes reaching an IOP control of $<21 \mathrm{mmHg}$ on final follow-up.
\end{abstract}

Conclusion. Glaucoma associated with acquired conditions was the most common childhood glaucoma in the patient population. Trabeculectomy was the most common surgery done. Trauma was the most prevalent cause of glaucoma from acquired conditions.

Key Words: childhood glaucoma, classification, pediatric glaucoma, prevalence of childhood glaucoma

\section{INTRODUCTION}

Paper presented at the PGH Department of Ophthalmology Resident Research Presentation, November 15, 2018, Sentro Oftalmologico Jose Rizal, Philippine General Hospital.

Corresponding author: Martin Joseph B. Babaran, MD Department of Ophthalmology and Visual Sciences Philippine General Hospital

University of the Philippines Manila

Taft Avenue, Manila 1000, Philippines

Email: martin.babaran@gmail.com

\section{Childhood Glaucoma}

Childhood glaucoma is a rare, multifactorial disease that leads to increased intraocular pressure and gradual blindness from optic nerve degeneration. It can be classified into primary or secondary childhood glaucoma. In primary childhood glaucoma, increased intraocular pressure is due to congenital, structural abnormalities, eventually impeding aqueous outflow. Secondary glaucoma can stem from different etiologies: trauma, aphakia, inflammation, and lens-associated disorders. ${ }^{1}$ Glaucoma at any age can eventually lead to permanent optic nerve damage, but the development of glaucoma at an early age is particularly devastating with associated damage to the visual system: refractive errors and amblyopia. 


\section{Definition of terms}

Childhood glaucoma is defined by the World Glaucoma Association in 2013 as a disease associated with increased intraocular pressure and damage to ocular structures. The age cut-off is based on different national criteria: in the United States, age $<18$ years, in the EU, UK, and UNICEF, it is defined as age $<16$ years. ${ }^{2}$ Childhood glaucoma is defined by 2 of the following features: intraocular pressure (IOP) greater than $21 \mathrm{mmHg}$, presence of optic disc cupping, and corneal findings of Haab striae, corneal edema, increased corneal diameter of greater than $11 \mathrm{~mm}$ in newborns, greater than $12 \mathrm{~mm}$ in children less than 1 year of age, and diameter of greater than $13 \mathrm{~mm}$ in any age. ${ }^{2}$ Other findings include progressive myopia from the increased ocular dimensions and a visual field defect from the optic neuropathy. ${ }^{2}$

\section{Classification of childhood glaucoma}

Childhood glaucoma was previously classified according to structural defects or etiologies, but previous systems did not encompass other etiologies such as acquired or systemic disorders., ${ }^{3,4}$ In 2013, the World Glaucoma Association developed an algorithm to classify glaucoma that encompasses different etiologies and one that applies to common scenarios of childhood glaucoma. This system developed through the Childhood Glaucoma Research Network (CGRN) classified childhood glaucoma according to 7 categories: 1) primary congenital glaucoma 2) juvenile open-angle glaucoma 3) glaucoma associated with acquired conditions 4) glaucoma associated with non-acquired systemic diseases or syndromes 5) glaucoma associated with non-acquired ocular anomalies 6) glaucoma following cataract surgery and 7) childhood glaucoma suspect. ${ }^{5}$ Definitions of which are described by Weinreb et al in the Consensus Guidelines in 2013. ${ }^{2}$

\section{Epidemiology}

Several studies have been done to determine the prevalence and incidence of childhood glaucoma in different population groups. In a study by the World Bank, documenting and classifying causes for blindness in the pediatric population, childhood glaucoma accounts for 5.5\% of the documented cause of blindness in children worldwide. ${ }^{6}$

The prevalence of childhood glaucoma was described in different populations. Childhood glaucoma was documented in population-based studies in the United Kingdom with the BIG study where they classified cases of glaucoma in patients aged $\leq 16$ years old. ${ }^{7}$ Population studies were also done in Olmstead, Minnesota USA. ${ }^{7,8}$ Single institution studies have also documented childhood glaucoma in Shanghai, China, Dahakelia, Egypt, Texas, Canada, USA, and South India. ${ }^{9-14}$ Recent studies done in Egypt and South India used the CGRN system to classify the patients. ${ }^{10,12}$

In the Philippines, two studies have profiled glaucoma patients in a tertiary hospital. Florcruz et al. in 2005 documented glaucoma patients from 2000 to 2002. Eighthundred thirty-six patients diagnosed with glaucoma were included in the study. Only 17 (2\%) patients were diagnosed with pediatric glaucoma. Seven patients with PCG, 6 with anterior segment dysgenesis, 4 with acquired glaucoma. ${ }^{15}$

Martinez and Hosaka documented the demographics and clinical profile of glaucoma patients seen in a single institution from 2010 to 2014. This study documented 577 patients with glaucoma. Glaucoma at a young age ( $\leq 20$ years) was documented in 22 (3.9\%) patients. Secondary glaucoma was the most common cause of glaucoma detected in the pediatric population at $18(82 \%)$ of the 22 cases: 3 were open-angle glaucoma and 1 was angle-closure glaucoma. No information was stated on the medical and surgical management of the cases in the pediatric population. ${ }^{16}$

There is a dearth of information on the incidence and characteristics of childhood glaucoma in the Philippines. There have been no previous attempts in the country to classify the patients diagnosed with childhood glaucoma. Analyzing characteristics including age, classification of the disease, initial age of diagnosis, intraocular pressure, medical and surgical management can provide baseline information for the future management of glaucoma patients in the country. Furthermore, the use of the CGRN classification scheme provides a simple, systematic, and communicable method of categorizing patients, especially in future prospective research.

\section{OBJECTIVES}

\section{General Objective}

Classify patients diagnosed with childhood glaucoma in a tertiary center using the CGRN classification scheme.

\section{Specific Objectives}

1. Describe the clinical profile of patients with childhood glaucoma including age, demographics of age, sex, age of diagnosis, intraocular pressure, initial presenting symptom.

2. Describe the medical and surgical treatments given to the patients.

3. Determine the change in intraocular pressure, via initial and final intraocular pressures in the pediatric glaucoma patients.

\section{MATERIALS AND METHODS}

\section{Setting}

Philippine General Hospital is a government-subsidized tertiary referral center in Manila, Philippines.

\section{Study design and duration}

A retrospective chart review of unique childhood glaucoma patients diagnosed and referred to the glaucoma service with an initial consult within January 2015 to December 2017 was done. Standardized data collection was done and tabulated into Microsoft Excel, Office 365 (Microsoft Corporation, USA). 


\section{Study Population}

\section{Inclusion criteria}

Patients diagnosed with glaucoma or glaucoma suspect and referred to the Glaucoma service with the age of $\leq 16$ years were included in the study.

\section{Exclusion Criteria}

Cases were excluded if there was insufficient data, defined as lacking more than 50\% (4 out of 6) of the following fields: age, sex, initial presenting symptom or reason for referral, quantified initial and follow-up intraocular pressure measured via Goldmann applanation tonometer (HaagStreit, Germany) or handheld Perkins tonometer (HaagStreit, Germany) or handheld ICare TAO1i tonometer (Icare, Finland). Diagnosis and recorded interventions were noted.

The characteristics of the patients diagnosed with glaucoma follow that of the CGRN guidelines, with at least two of the following features: intraocular pressure greater than $21 \mathrm{mmHg}$, presence of optic disc cupping, corneal findings of Haab striae, corneal edema, increased corneal diameter of $>11 \mathrm{~mm}$ in newborns, $>12 \mathrm{~mm}$ in children $<1$ year of age, and diameter of $>13 \mathrm{~mm}$ in any age. ${ }^{2}$ Other findings include progressive myopia or myopic shift from the increased ocular size and dimensions and a visual field defect from the optic neuropathy. ${ }^{2}$

Patients with glaucoma suspect were diagnosed with the following characteristics according to the CGRN guidelines: 1) $\mathrm{IOP}>21 \mathrm{mmHg}$ on two different recordings, 2) optic disc findings suggestive of glaucoma 3) recorded visual field findings suggestive of glaucoma, and 4) increased corneal diameter or axial length with the presence of normal IOP. ${ }^{2}$

\section{Data Collection}

An approval from the Research Ethics Board was obtained before the start of the data collection to assure that the research will adhere to the codes of the Declaration of Helsinki. Confidentiality and anonymity of patients during retrospective chart review were maintained according to the National Ethical Guidelines for Health and Health-related Research (NEGHHR 2017). ${ }^{17}$ The Sentro Oftalmologico Jose Rizal (SOJR) holds records of all ophthalmologic patients referred to the glaucoma service from 2015 to 2017. Charts of patients who have been referred to the glaucoma service at the age of 16 and below were secured. ${ }^{7}$ Baseline characteristics of the patients were obtained, including age, sex, age of presentation, visual acuity, and laterality of the disease. Intraocular pressure (IOP) was obtained via Goldmann applanation tonometer, (Haag-Streit AG, UK) handheld Perkins tonometer (Haag-Streit AG, UK), or handheld ICare TAO1i tonometer (Icare, Finland). Initial and latest diagnoses recorded in the chart were noted. The follow-up period was recorded as the duration from the initial to the latest consult. The chief complaint or reason for a referral if referred from a subspecialty service to the glaucoma center was obtained. The medical and surgical interventions for the patients as well as the follow-up intraocular pressure were recorded. Data privacy was upheld by assigning a unique numerical code for each patient with case numbers recorded for data review and verification by an ethics board. Review of data was done within the premises of the medical records section of SOJR. Data was stored in a passwordprotected computer and destroyed within 5 years.

The diagnoses of the patients were further categorized into one of 6 categories using the CGRN definitions (Figure 1). Patients who exhibited signs of glaucoma only after cataract surgery, but without any underlying etiologies were categorized into glaucoma after cataract surgery. The patients were then reclassified according to glaucoma from non-acquired conditions. Patients with histories of glaucoma associated with acquired diseases (trauma, uveitis, ROP) were categorized. The patients with findings of buphthalmos or documented with Haab striae were reclassified into primary congenital glaucoma (PCG), and the remaining patients with no signs of buphthalmos were reclassified into juvenile open-angle glaucoma (JOAG). The patients who only satisfied at least one of the conditions for glaucoma were classified as glaucoma suspects. (Figure 1)

Data analysis of categorical data (sex, number of glaucoma medications, laterality) were presented as frequency distributions via means and medians. Statistical analysis on the comparison of means in final intraocular pressure on patients treated medically and surgically was done through Microsoft Excel 2016 Office 365 (Microsoft Corporation, USA). Means were compared using unpaired t-test of unequal variance with OpenEpi Open source statistical tool (Emory University, USA). ${ }^{18}$

\section{Outcomes}

The primary outcome to be determined is the classification of patients using the CGRN system. Additional outcomes to describe the patients were baseline characteristics of the patients: sex, laterality of affected eye, initial intraocular pressure, initial presenting symptom, medical and surgical interventions, and the final intraocular pressure.

\section{Limitations}

Since the study is a retrospective chart review, the research is limited solely to the available data. Classification according to the CRGN algorithm is based on good recordkeeping of the clinical history, physical examination, and course in the chart.

\section{RESULTS}

One hundred (100) charts were located with an initial consult from January 2015 to December 2017 with a diagnosis of pediatric glaucoma or with findings that were eligible within the CGRN guidelines. Twenty-three charts 


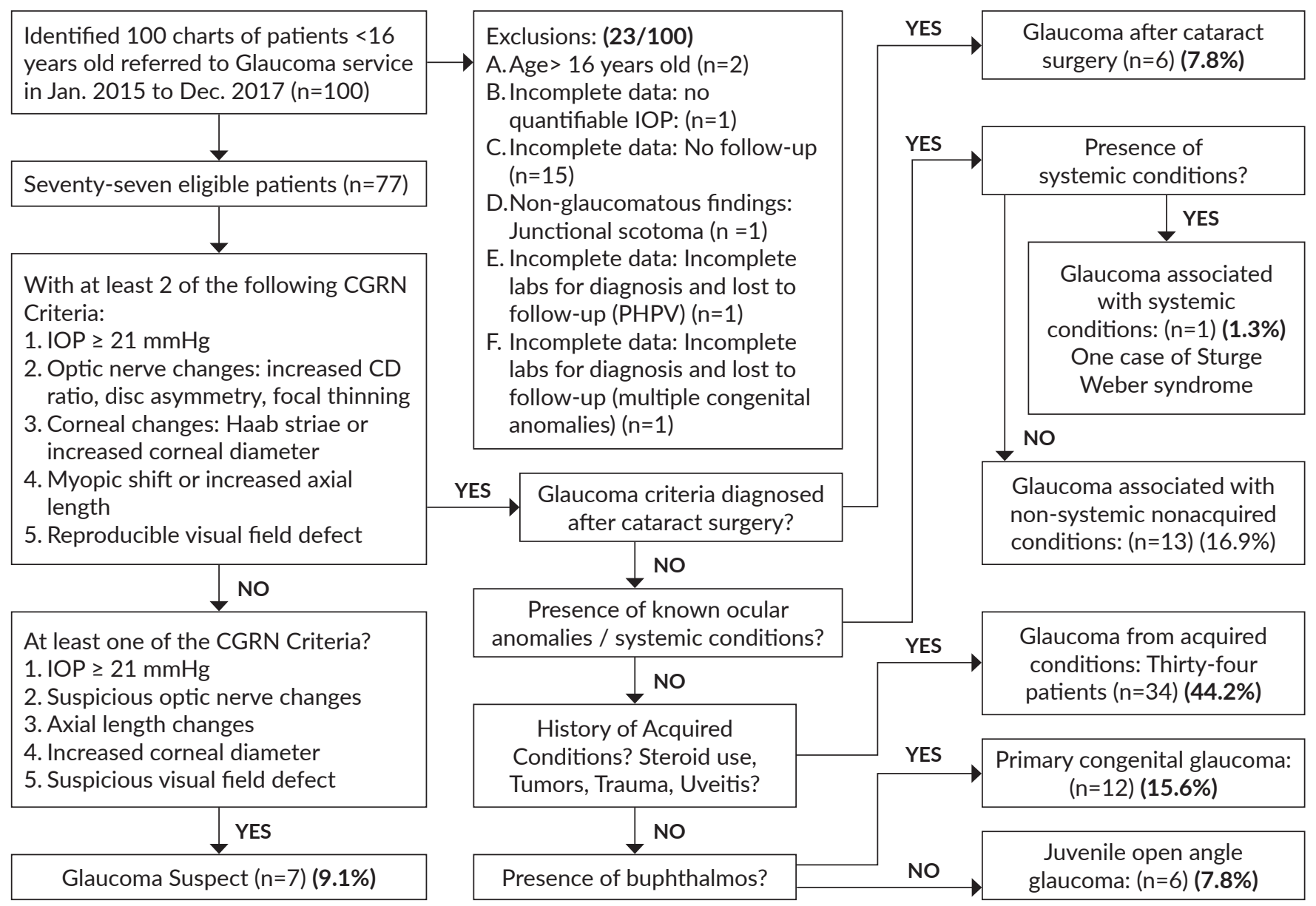

Figure 1. Flowchart for categorizing patients using the CGRN classification scheme from Beck, $2013 .^{2}$

were excluded, 2 were excluded due to age: both were consulted and were diagnosed as congenital glaucoma at age 17 and 22, respectively. Sixty-five percent of the cases (15 of the 23 charts) had incomplete data with no data on follow-up. One patient was found to have junctional scotoma on automated perimetry and was reclassified as a neuro-ophthalmology case. The rest of the patients had incomplete data with no IOP recorded, no follow-up, no corneal dimensions from which the initial diagnosis could not be crosschecked, which cannot be compared to the CGRN criteria for classification. Two cases were referred to the glaucoma service but the findings did not satisfy any CGRN criteria for glaucoma or glaucoma suspect, these cases were also lost to follow-up and without documentation of disc photo or perimetry. (Figure 1)

\section{Baseline characteristics of patients}

Seventy-seven cases were included in the data analysis, of which, 27 (35.1\%) were bilateral. The majority of the cases referred to the service were of glaucoma from acquired conditions at $44.2 \%$ of the cases. There is a male predilection in this set of patients: $44(63.6 \%)$ cases were male, with an average age of $8.09 \pm 4.67$ years. (Table 1 )

\section{Reason for the consult}

The most common reason is an incidental finding of increased IOP in 23 patients (29.9\%), seen in 14 of 23 cases from glaucoma from acquired conditions and 5 from glaucoma after cataract surgery. Most of these cases were already on follow-up within the institution and were referred to the glaucoma service for further intervention. Changes in eye dimensions (buphthalmos) were noted in 7 (58.3\%) of 12 cases of congenital glaucoma.

\section{Primary congenital glaucoma}

Twelve patients (15.6\%) satisfied the criteria solely for PCG. Patients were classified into 3 classifications based on the age of presentation. The average corneal diameter is $13.5 \pm 1.85 \mathrm{~mm}$ in all affected eyes and was documented in 15 of 19 eyes (78.9\%). The reason for the initial consult for 7 of the 12 cases $(58.3 \%)$ is a change in eye dimensions: buphthalmos, with 3 of the 12 cases with corneal haze $(25 \%)$. One patient was initially classified as uveitic glaucoma, but there were no documented findings of uveitis such as band keratopathy or characteristics of anterior segment inflammation. The patient only had descriptions of buphthalmos on initial examination and follow-up hence 
Table 1. Demographic characteristics of patients included in the study

\begin{tabular}{|c|c|c|c|c|c|c|c|c|}
\hline CGRN Classification & $\begin{array}{l}\text { Number } \\
\text { of Patients } \\
(\%)\end{array}$ & $\begin{array}{c}\text { Sex } \\
\text { (Male: } \\
\text { female) }\end{array}$ & $\begin{array}{c}\text { Age } \\
\text { (years) } \\
\text { Mean } \pm S D\end{array}$ & $\begin{array}{l}\text { Number of } \\
\text { days follow-up } \\
\text { Mean } \pm \text { SD }\end{array}$ & $\begin{array}{l}\text { Bilateral: } \\
\text { Unilateral } \\
\text { (Number } \\
\text { of eyes) }\end{array}$ & $\begin{array}{l}\text { Initial Recorded } \\
\text { Intraocular } \\
\text { Pressure in } \\
\text { affected eyes } \\
(\mathrm{mmHg}) \text { Mean } \pm \text { SD }\end{array}$ & $\begin{array}{c}\text { Final Recorded } \\
\text { Intraocular } \\
\text { pressure in } \\
\text { affected eyes } \\
(\mathrm{mmHg}) \text { Mean } \pm \text { SD }\end{array}$ & $\begin{array}{l}\text { p-value } \\
(\mathrm{Cl}>95 \%)\end{array}$ \\
\hline $\begin{array}{l}\text { Primary Congenital } \\
\text { Glaucoma }\end{array}$ & $\begin{array}{c}n=12 \\
(15.6 \%)\end{array}$ & $7: 5$ & $5.2 \pm 5.4$ & $474.4 \pm 391.2$ & $7: 5$ (19) & $\begin{array}{c}30.2 \pm 14.3 \\
(n=19)\end{array}$ & $\begin{array}{c}21.1 \pm 15.4 \\
(n=19)\end{array}$ & 0.069 \\
\hline $\begin{array}{l}\text { Juvenile Open Angle } \\
\text { Glaucoma }\end{array}$ & $\begin{array}{c}n=4 \\
(5.2 \%)\end{array}$ & $4: 0$ & $14.5 \pm 1.3$ & $522.5 \pm 330.4$ & $3: 1(7)$ & $\begin{array}{c}35.4 \pm 15.8 \\
(n=7)\end{array}$ & $\begin{array}{c}7.8 \pm 3.8 \\
(n=7)\end{array}$ & 0.00072 \\
\hline $\begin{array}{l}\text { Glaucoma from } \\
\text { Acquired conditions }\end{array}$ & $\begin{array}{c}n=34 \\
(44.2 \%)\end{array}$ & $21: 13$ & $9.4 \pm 3.5$ & $399.2 \pm 393.3$ & $4: 30(38)$ & $\begin{array}{c}33.4 \pm 13.9 \\
(n=38)\end{array}$ & $\begin{array}{c}14.0 \pm 9.4 \\
(n=38)\end{array}$ & $<0.0000001$ \\
\hline $\begin{array}{l}\text { Glaucoma from } \\
\text { non-acquired } \\
\text { systemic conditions }\end{array}$ & $\begin{array}{c}n=1 \\
(1.3 \%)\end{array}$ & $0: 1$ & 0.5 & 119 & $0: 1(1)$ & $\begin{array}{c}24 \\
(n=1)\end{array}$ & $\begin{array}{c}17 \\
(n=1)\end{array}$ & - \\
\hline $\begin{array}{l}\text { Glaucoma from } \\
\text { non-acquired non- } \\
\text { systemic conditions }\end{array}$ & $\begin{array}{c}n=13 \\
(16.9 \%)\end{array}$ & $8: 5$ & $5.7 \pm 4.7$ & $418.5 \pm 380.7$ & 3:10 (16) & $\begin{array}{c}26.5 \pm 13.9 \\
(n=16)\end{array}$ & $\begin{array}{c}20.7 \pm 12.1 \\
(n=16)\end{array}$ & 0.23 \\
\hline $\begin{array}{l}\text { Glaucoma following } \\
\text { cataract surgery }\end{array}$ & $\begin{array}{c}n=6 \\
(7.8 \%)\end{array}$ & $5: 0$ & $8 \pm 4.3$ & $520.7 \pm 333.6$ & $3: 3(9)$ & $\begin{array}{c}26.9 \pm 10.5 \\
(n=9)\end{array}$ & $\begin{array}{c}23.0 \pm 12.2 \\
(n=9)\end{array}$ & 0.49 \\
\hline All glaucoma & $\begin{array}{c}n=70 \\
(90.9 \%)\end{array}$ & $45: 25$ & $8.0 \pm 4.7$ & $429.1 \pm 374.0$ & $18: 52(90)$ & $\begin{array}{c}30.9 \pm 13.8 \\
(n=90)\end{array}$ & $\begin{array}{c}17.2 \pm 12.0 \\
(n=90)\end{array}$ & $<0.0000001$ \\
\hline Glaucoma suspect & $\begin{array}{c}\mathrm{n}=7 \\
(9.1 \%)\end{array}$ & $4: 3$ & $9.0 \pm 4.9$ & $291.3 \pm 402.6$ & $7: 0$ (14) & $\begin{array}{c}17.0 \pm 6.1 \\
(n=14)\end{array}$ & $\begin{array}{c}14.0 \pm 6.5 \\
(n=14)\end{array}$ & 0.17 \\
\hline Total & $\begin{array}{c}n=77 \\
(100 \%)\end{array}$ & $49: 28$ & $8.1 \pm 4.7$ & $416.6 \pm 376.0$ & $25: 52(104)$ & $\begin{array}{c}29.0 \pm 13.8 \\
(n=104)\end{array}$ & $\begin{array}{c}16.7 \pm 11.4 \\
(n=104)\end{array}$ & $<0.0000001$ \\
\hline
\end{tabular}

reclassification into late PCG. The youngest patient who matched the criteria for PCG was aged 2 weeks, and the oldest patient was diagnosed at 15 years old.

\section{Juvenile open-angle glaucoma}

Four patients satisfied the criteria for PCG but without any signs or record of changes in corneal diameter or no documented buphthalmos. All patients were male and 3 of the 4 cases were bilateral. The most common complaints were blurring of vision and eye redness. The average cup disc ratio was 0.825 . One patient was initially referred from the general ophthalmology clinic for recorded disc changes but with no recorded enlargement of corneal diameter. This patient had no recorded visual field changes but had subsequent trabeculectomies for both eyes on follow-up. JOAG patients had the highest average age at $14.5 \pm 1.3$ years.

\section{Glaucoma is associated with acquired conditions}

The majority of the childhood glaucoma cases included in the study are from acquired conditions at 34 patients (44.2\%). There is a 1.62:1 male to female predilection for these cases and 30 of 34 (88.24\%) of these cases are unilateral. The most common cause of secondary glaucoma in this group is trauma at 15 of 34 cases (44.12\%), with 14 of the 15 cases were unilateral. Angle recession glaucoma and traumatic hyphema from the cases consist of the largest portion of the glaucoma cases secondary to trauma at $6(17.6 \%)$ cases each. Notably, there were more cases of trauma (15) than that of primary childhood glaucoma (12).
Seven of the 34 cases $(20.6 \%)$ were secondary to retinal or corneal surgeries, with 4 of the 7 cases occurring after penetrating keratoplasty (PKP), and 3 with retinal surgery.

There were 5 eyes in 3 steroid responder patients. Two of 3 patients presented with documented increased IOP after steroid use and were subsequently referred to the glaucoma clinic. There is one case of a unilateral corneal scar with secondary angle closure in a 15 -year-old. The patient had 360 -degree closed angles with a visual acuity of 20/400 and an initial IOP of $34 \mathrm{mmHg}$ before therapy.

Five patients were classified into acquired glaucoma from uveitic conditions. There is a 1.5:1 male to female ratio and all 5 cases were unilateral. The initial reason for referral for these cases is blurring of vision in 2 of the 5 cases, 2 with eye pain, with eye redness. Vision for these eyes ranged from no light perception (NLP) to hand movement. One patient was previously diagnosed as uveitic glaucoma but was reclassified into primary congenital glaucoma due to presence of buphthalmos and no record of signs of anterior segment inflammation in any follow-up.

Three patients were noted secondary to malignancies. One case was of a 6-year-old male, with acute lymphocytic leukemia who initially presented with eye redness, with qualitative findings of hyphema, corneal staining, and corneal edema with an initial documented IOP of $32.33 \mathrm{mmHg}$ $\left(\right.$ Icare $\left.^{\circledR}\right)$. Another case was that of a 3-year-old female with proptosis and increased IOP (average of $23 \mathrm{mmHg}$ initially) with progression on follow-up $(33.50 \mathrm{mmHg}$ average for both eyes). The patient was noted to have an intracranial 
mass with increased IOP $>21 \mathrm{mHg}$ from the extraocular mass. The last patient described in a case report by Sosuan in 2018 was that of a 10-year-old female with a history of blunt trauma, eye pain, and proptosis. The patient was initially managed as a case of panophthalmitis with increased IOP. Persistent eye pain and poor vision led to enucleation and histopathologic analysis of the eye showed necrosis and round blue cells with synaptophysin on immunohistochemistry, consistent with retinoblastoma. ${ }^{19}$

\section{Glaucoma is associated with non-acquired systemic conditions}

Only one patient was classified into this category. The patient was a female diagnosed with Sturge-Weber Syndrome. The patient was initially referred to the pediatrics department for seizures and was referred to the ophthalmology department for unilateral photophobia. The patient had an Icare ${ }^{\circledR}$ intraocular pressure of $24 \mathrm{mmHg}$ on the affected eye and $17 \mathrm{mmHg}$ on the other eye. Gonioscopic findings were not recorded on initial and on follow up for this patient. Corneal findings were not recorded for this patient in the initial and follow-up consults.

\section{Glaucoma-associated with non-acquired ocular conditions}

Thirteen patients were classified into this category, with one case of aniridia, 4 cases of anterior segment dysgenesis, 3 patients with ectopia lentis, one case of bilateral ectropion uveae, 2 cases of iris cyst, and 1 case of neurotrophic keratopathy. The case with congenital ectropion uveae was initially diagnosed as a case of PCG with recorded findings of ectropion uveae on follow-up led to the patient's reclassification. Eye pain was the primary complaint. The patients with congenital neurotrophic keratopathy and Peters anomaly were referred for the incidental finding of increased IOP > $21 \mathrm{mmHg}$ at the initial consult.

\section{Glaucoma following cataract surgery}

Six patients were noted to have criteria for classification for glaucoma but the signs only occurred after cataract surgery. Three of the six cases (50\%) were aphakic, and the rest include one posterior capsule intraocular lens, one with an anterior chamber intraocular lens, and one sulcus intraocular lens. The reason for referral for 5 of $6(83.3 \%)$ cases was documented elevated IOP. The average age of the patients is $8.0 \pm 4.3$ years, and there is a 1:5 male to female ratio the average cup to disc ratio for affected eyes is $0.45 \pm 0.12$.

\section{Glaucoma suspect}

Seven (10\%) of the included 77 cases were classified as a glaucoma suspect. These patients either had increased intraocular pressure $>21 \mathrm{mmHg}$ or an increased cup disc ratio. The primary chief complaint of the patients was increased cup to disc ratio in 4 of the 7 cases (57.1\%), while the other complaints include eye pain (14.3\%), blurring of vision
(14.3\%), and elevated IOP (14.3\%). In these cases, refraction was unfortunately not done or recorded.

\section{Treatment and follow-up}

\section{Surgical interventions}

Thirty-one eyes out of the 77 (40.1\%) included in the study received primary surgical interventions. Trabeculectomy was the primary surgical intervention in 20 (19.4\%) eyes, done in 9 of 19 eyes in primary childhood glaucoma, 6 in juvenile open-angle glaucoma, 4 in secondary glaucoma from acquired conditions, and 1 aphakic eye. Primary glaucoma drainage device (GDD) implantation was done in 4 (3.9\%) eyes: two late PCG eyes, one aphakic eye, and one postPKP eye. Anterior chamber washout was done in 3 (2.88\%) cases: hyphema, iris cyst, one post-retinal surgery eye. Laser iridotomy was done in a post-PKP patient, peripheral iridotomy was done in a patient with an iris cyst. One patient underwent silicone oil removal for glaucoma associated with retinal surgery. Secondary GDD implantation was done in 3 primary congenital glaucoma patients who underwent initial trabeculectomy and in one patient with a corneal perforating injury with prior trabeculectomy.

\section{Medical Interventions}

Beta-blockers were the most commonly used medications, in the form of betaxolol (76.9\%), followed by topical carbonic anhydrase inhibitors (CAI) (45.2\%). Patients used $2.5 \pm 1.3$ medications per eye. Oral CAI (Acetazolamide) was used in 15 total patients (19.5\%). Fifty-five patients underwent purely medical interventions compared to 31 patients who received a primary surgical intervention. Surgical interventions had a mean change of $-22.33 \pm 16.75$ $\mathrm{mmHg}$ compared to medical interventions, $-9.32 \pm 17.35$ $\mathrm{mmHg}$. Comparison using independent T-test showed a statistically significant difference in mean change in IOP in surgical interventions compared to medical interventions ( $\mathrm{p}$-value at a 95\% confidence interval of 0.0011). ${ }^{18}$

\section{Visual Acuity}

Visual acuity was obtained in cooperative children via Snellen, HOTV optotypes, or equivalent LEA symbols in 72 of 104 eyes (69.2\%). Fixation behavior was documented in uncooperative or preverbal patients in 32 eyes (30.8\%). This is comparable with other studies that had difficulty in recording visual acuity in $13.8 \%-36.7 \%$ of eyes. ${ }^{9}, 10$ (Table 2) Fifty-one eyes (49.0\%) were initially documented to have a visual acuity of at least 20/200, with 2 of 104 eyes initially with no light projection, one patient with uveitis and one patient with ectopia lentis.

On the final follow-up, there was an increase in documented eyes with Snellen or HOTV optotype with 81 eyes (77.9\%), however, there was an increase in documented eyes with vision at no light projection in 8 eyes: 1 late PCG, 1 post-PKP, one blind eye in a patient with retino- 
Table 2. Initial recorded visual acuity

\begin{tabular}{|c|c|c|c|c|c|c|c|}
\hline \multirow{2}{*}{$\begin{array}{l}\text { CGRN classification } \\
\text { (no. of eyes) }\end{array}$} & \multicolumn{3}{|c|}{ Verbal } & \multicolumn{3}{|c|}{ Preverbal } & \multirow[b]{2}{*}{ Total } \\
\hline & $\begin{array}{l}20 / 20 \text { to } \\
20 / 40\end{array}$ & $\begin{array}{l}20 / 50 \text { to } \\
20 / 200\end{array}$ & $\begin{array}{l}\text { Worse than } \\
20 / 200^{+}\end{array}$ & $\begin{array}{l}\text { Fixates and } \\
\text { follows }\end{array}$ & Dazzle & $\begin{array}{c}\text { Could not } \\
\text { be assessed }\end{array}$ & \\
\hline $\begin{array}{l}\text { Primary congenital } \\
\text { glaucoma }(n=19)\end{array}$ & $0(0.0 \%)$ & 2 (10.5\%) & $8(42.1 \%)$ & $0(0.0 \%)$ & $8(42.1 \%)$ & $1(5.3 \%)$ & $19(100 \%)$ \\
\hline $\begin{array}{l}\text { Juvenile open angle } \\
\text { glaucoma }(n=7)\end{array}$ & $2(28.6 \%)$ & $2(28.6 \%)$ & $3(42.9 \%)$ & $0(0.0 \%)$ & $0(0.0 \%)$ & $0(0.0 \%)$ & $7(100 \%)$ \\
\hline $\begin{array}{l}\text { Glaucoma associated with } \\
\text { acquired conditions }(n=38)\end{array}$ & $9(23.7 \%)$ & $10(26.3 \%)$ & $14(36.8 \%)$ & $1(2.6 \%)$ & $3(7.9 \%)$ & $1(2.6 \%)$ & $38(100 \%)$ \\
\hline $\begin{array}{l}\text { Glaucoma from non- } \\
\text { acquired systemic } \\
\text { conditions }(n=1)\end{array}$ & $0(0.0 \%)$ & $0(0.0 \%)$ & $0(0.0 \%)$ & $1(100 \%)$ & $0(0.0 \%)$ & $0(0.0 \%)$ & $1(100 \%)$ \\
\hline $\begin{array}{l}\text { Glaucoma from non- } \\
\text { acquired non-systemic } \\
\text { conditions }(n=16)\end{array}$ & $0(0.0 \%)$ & $0(0.0 \%)$ & $5(31.3 \%)$ & $4(25.0 \%)$ & $2(12.5 \%)$ & $5(31.3 \%)$ & $16(100 \%)$ \\
\hline $\begin{array}{l}\text { Glaucoma following } \\
\text { cataract surgery }(n=9)\end{array}$ & $0(0.0 \%)$ & $3(33.3 \%)$ & $2(22.2 \%)$ & $3(33.3 \%)$ & 1 (11.1\%) & $0(0.0 \%)$ & 9 (100\%) \\
\hline All glaucoma $(n=90)$ & $11(12.2 \%)$ & 17 (18.9\%) & $32(35.6 \%)$ & $9(10.0 \%)$ & $14(15.6 \%)$ & $7(7.8 \%)$ & $90(100 \%)$ \\
\hline Glaucoma suspect $(n=14)$ & 8 (57.1\%) & $4(28.6 \%)$ & $0(0.0 \%)$ & $0(0.0 \%)$ & $2(14.33 \%)$ & $0(0.0 \%)$ & $14(100 \%)$ \\
\hline All patients $(n=104)$ & 19 (18.3\%) & $21(20.2 \%)$ & $32(30.8 \%)$ & $9(8.7 \%)$ & $16(15.5 \%)$ & $7(6.7 \%)$ & $104(100 \%)$ \\
\hline
\end{tabular}

+: includes counting fingers, hand movement, light projection, light perception and no light perception

Table 3. Final recorded visual acuity

\begin{tabular}{|c|c|c|c|c|c|c|c|}
\hline \multirow{2}{*}{$\begin{array}{l}\text { CGRN classification } \\
\text { (no. of eyes) }\end{array}$} & \multicolumn{3}{|c|}{ Verbal } & \multicolumn{3}{|c|}{ Preverbal } & \multirow[b]{2}{*}{ Total } \\
\hline & $\begin{array}{l}20 / 20 \text { to } \\
20 / 40\end{array}$ & $\begin{array}{l}20 / 50 \text { to } \\
20 / 200\end{array}$ & $\begin{array}{c}\text { Worse than } \\
20 / 200^{+}\end{array}$ & $\begin{array}{l}\text { Fixates and } \\
\text { follows }\end{array}$ & Dazzle & $\begin{array}{c}\text { Could not } \\
\text { be assessed }\end{array}$ & \\
\hline $\begin{array}{l}\text { Primary congenital } \\
\text { glaucoma }(n=19)\end{array}$ & 0 & $5(26.3 \%)$ & $4(21.1 \%)$ & $2(10.5 \%)$ & $7(36.8 \%)$ & $1(5.3 \%)$ & 19 (100\%) \\
\hline $\begin{array}{l}\text { Juvenile open angle } \\
\text { glaucoma }(n=7)\end{array}$ & $2(28.6 \%)$ & $2(28.6 \%)$ & $3(42.9 \%)$ & $0(0.0 \%)$ & $0(0.0 \%)$ & $0(0.0 \%)$ & $7(100 \%)$ \\
\hline $\begin{array}{l}\text { Glaucoma associated with } \\
\text { acquired conditions }(n=38)\end{array}$ & $12(31.6 \%)$ & $5(13.2 \%)$ & $15(39.5 \%)$ & $1(2.6 \%)$ & $5(13.2 \%)$ & $0(0.0 \%)$ & $38(100 \%)$ \\
\hline $\begin{array}{l}\text { Glaucoma from non- } \\
\text { acquired systemic } \\
\text { conditions }(n=1)\end{array}$ & 0 (0.0\%) & 0 (0.0\%) & $1(100 \%)$ & $0(0.0 \%)$ & 0 (0.0\%) & 0 (0.0\%) & 1 (100\%) \\
\hline $\begin{array}{l}\text { Glaucoma from non- } \\
\text { acquired non-systemic } \\
\text { conditions }(n=16)\end{array}$ & 0 (0.0\%) & 1 (6.3\%) & $7(43.8 \%)$ & 1 (6.3\%) & 2 (12.5\%) & $5(31.3 \%)$ & $16(100 \%)$ \\
\hline $\begin{array}{l}\text { Glaucoma following } \\
\text { cataract surgery }(n=9)\end{array}$ & 1 (11.1\%) & $5(55.6 \%)$ & $1(11.1 \%)$ & $2(22.2 \%)$ & 0 (0.0\%) & $0(0.0 \%)$ & $9(100 \%)$ \\
\hline All glaucoma $(n=90)$ & $9(64.3 \%)$ & $3(21.4 \%)$ & $0(0.0 \%)$ & $0(0.0 \%)$ & $2(14.3 \%)$ & $0(0.0 \%)$ & $14(100 \%)$ \\
\hline Glaucoma suspect $(n=14)$ & $15(16.7 \%)$ & $18(20.0 \%)$ & $31(34.4 \%)$ & $6(6.7 \%)$ & $14(15.6 \%)$ & $6(6.7 \%)$ & $90(100 \%)$ \\
\hline All patients $(n=104)$ & $24(23.1 \%)$ & $21(20.2 \%)$ & $31(29.9 \%)$ & $6(5.8 \%)$ & $16(15.4 \%)$ & $6(5.8 \%)$ & $104(100 \%)$ \\
\hline
\end{tabular}

+: includes counting fingers, hand movement, light projection, light perception and no light perception

blastoma, 2 patients with uveitis, one patient with ectopia lentis, one case of iris cyst and once a case of PHPV (persistent hyperplastic primary vitreous). ${ }^{13}$ An improvement in recorded Snellen visual acuity was observed in PCG. Initially, $10.5 \%$ of eyes in PCG had a visual acuity of at least 20/200, on the final follow-up this improved to $26.3 \%$ of eyes (Table 3). Glaucoma following cataract surgery had the best visual outcomes with 6 of 9 eyes (66.7\%) achieving a final VA of better than 20/200, and only one patient (11.1\%) attaining a visual acuity of less than 20/200 (Table 3).

\section{Primary congenital glaucoma}

Eleven of 19 eyes underwent surgical intervention, with 9 (47.4\%) eyes undergoing primary trabeculectomy, 2 eyes (10.5\%) undergoing primary GDD, and 3 of 11 (27.2\%) eyes underwent secondary GDD. Diode cyclophotocoagulation was done in a late glaucoma patient who underwent multiple surgeries of primary trabeculectomy and secondary GDD implantation. The mean recorded IOP on the final followup was $21.1 \pm 15.4 \mathrm{mmHg}$, where 10 of 11 eyes (90.1\%) that underwent surgical intervention reached a target IOP of below $21 \mathrm{mmHg}$ compared to only 4 of 8 eyes (50.0\%) that underwent medical interventions. 


\section{Juvenile open-angle glaucoma}

All 7 eyes achieved an IOP of below $21 \mathrm{mmHg}$ on the final follow-up. Juvenile open-angle glaucoma had the highest average change in intraocular pressure after interventions at $27.6 \pm 16.0 \mathrm{mmHg}$. Examination under anesthesia (EUA) was done in 2 of the 4 cases, and one patient underwent automated visual field testing (AVF). Topical medications included timolol, brinzolamide, and latanoprost. Two of the four patients needed 4 medications including oral acetazolamide. Trabeculectomy was the primary surgical intervention in 3 of the 4 cases, one case was not able to undergo surgical intervention. Eyes with JOAG had the lowest average final $\mathrm{IOP}$ at $7.8 \pm 3.8 \mathrm{mmHg}$ out of all known groups.

\section{Glaucoma associated with acquired conditions}

Intraocular pressure improved on follow-up at 14.0 \pm 9.4 $\mathrm{mmHg}$ from an initial of $33.4 \pm 13.9 \mathrm{mmHg}$ with an average difference of $18.7 \pm 17.9 \mathrm{mmHg}$. Primary trabeculectomy was the most common intervention done in 4 of the 38 eyes $(10.5 \%)$. Nine eyes underwent primary surgical interventions:
4 eyes underwent primary trabeculectomy: one case of angle recession, one steroid responder, and one patient. Another post-CPI patient underwent trabeculectomy and a subsequent secondary GDD implant. Anterior chamber washout was done in one hyphema patient and in a patient with anterior chamber bleed with post-enucleation findings of retinoblastoma. ${ }^{19}$ Silicone oil removal was done in a postretina surgery patient. Eight out of the 9 (88.9\%) eyes that underwent surgical interventions had an IOP of below $21 \mathrm{mmHg}$ on the final follow-up. Twenty-six eyes of 38 (68.4\%) underwent medical interventions only, with $80.8 \%$ of eyes achieving an intraocular pressure of below $21 \mathrm{mmHg}$. Fifteen of 38 eyes $(39.5 \%)$ had recorded vision of less than $20 / 200$, with 12 of 38 eyes (31.5\%) with a vision of hand movement or less, with 3 cases of NLP.

\section{Glaucoma associated with non-acquired systemic conditions}

The patient was managed medically and maintained an IOP of $>21 \mathrm{mmHg}$ on follow-up. The cup-disc ratio

Table 4. Comparison of intraocular pressure on initial and final follow-ups according to type of intervention

\begin{tabular}{|c|c|c|}
\hline CGRN Classification (in number of eyes) & $\begin{array}{l}\text { Eyes with intraocular pressure above } \\
21 \mathrm{mmHg}(\%) \text { on initial follow-up }\end{array}$ & $\begin{array}{l}\text { Eyes with } 13 \text { intraocular pressure above } \\
21 \mathrm{mmHg}(\%) \text { on final follow-up }\end{array}$ \\
\hline $\begin{array}{l}\text { Primary congenital glaucoma } \\
\text { Surgical: } 11 \\
\text { Medical: } 8 \\
\text { No intervention: } 0 \\
\text { Total } 19\end{array}$ & $\begin{array}{l}\text { Surgical: } 8(72.7) \\
\text { Medical: } 5(62.5) \\
\text { No intervention: } 0(0.0) \\
\text { Total: } 13(68.4)\end{array}$ & $\begin{array}{l}\text { Surgical: } 1(9.1) \\
\text { Medical: } 4(50.0) \\
\text { No intervention } 0(0.0) \\
\text { Total: } 5 \text { (26.3) }\end{array}$ \\
\hline $\begin{array}{l}\text { Juvenile open angle glaucoma } \\
\text { Surgical: } 6 \\
\text { Medical: } 0 \\
\text { No intervention: } 1 \\
\text { Total: } 7\end{array}$ & $\begin{array}{l}\text { Surgical: } 5(83.3) \\
\text { Medical: } 0(0.0) \\
\text { No intervention: } 0(0.0) \\
\text { Total: } 5(71.4)\end{array}$ & $\begin{array}{l}\text { Surgical: } 0(0.0) \\
\text { Medical: } 0(0.0) \\
\text { No intervention: } 0(0.0) \\
\text { Total: } 0(0.0)\end{array}$ \\
\hline $\begin{array}{l}\text { Glaucoma from acquired conditions } \\
\text { Surgical: } 9 \\
\text { Medical: } 26 \\
\text { No intervention: } 3 \\
\text { Total: } 38\end{array}$ & $\begin{array}{l}\text { Surgical: } 9(100.0) \\
\text { Medical: } 20(76.9) \\
\text { No intervention: } 0(0.0) \\
\text { Total: } 29 \text { (76.3) }\end{array}$ & $\begin{array}{l}\text { Surgical: } 1(11.1)^{*} \\
\text { Medical: } 5 \text { (19.2) } \\
\text { No intervention: } 0(0.0) \\
\text { Total: } 5 \text { (13.5) }\end{array}$ \\
\hline $\begin{array}{l}\text { Glaucoma from non-acquired systemic conditions } \\
\text { Surgical: } 0 \\
\text { Medical: } 1 \\
\text { No intervention: } 0 \\
\text { Total: } 1\end{array}$ & $\begin{array}{l}\text { Surgical: } 0 \\
\text { Medical: } 1 \text { (100.0) } \\
\text { No intervention: } 0 \text { (0.0) } \\
\text { Total: } 1 \text { (100.0) }\end{array}$ & $\begin{array}{l}\text { Surgical:0 } \\
\text { Medical: } 0(0.0) \\
\text { No intervention: } 0(0.0) \\
\text { Total: } 0(0.0)\end{array}$ \\
\hline $\begin{array}{l}\text { Glaucoma from non-acquired non-systemic conditions } \\
\text { Surgical: } 3 \\
\text { Medical: } 13 \\
\text { No intervention: } 0 \\
\text { Total: } 16\end{array}$ & $\begin{array}{l}\text { Surgical: } 2 \text { (66.7) } \\
\text { Medical: } 9 \text { (69.2) } \\
\text { No intervention: } 0(0.0) \\
\text { Total: } 11 \text { (68.8) }\end{array}$ & $\begin{array}{l}\text { Surgical: } 1 \text { (33.3) } \\
\text { Medical } 5 \text { (38.5) } \\
\text { No intervention: } 0(0.0) \\
\text { Total: } 6 \text { (40.0) }\end{array}$ \\
\hline $\begin{array}{l}\text { Glaucoma following cataract surgery } \\
\text { Surgical: } 2 \\
\text { Medical: } 7 \\
\text { No intervention:0 } \\
\text { Total: } 9\end{array}$ & $\begin{array}{l}\text { Surgical: } 1 \text { (50.0) } \\
\text { Medical: } 3 \text { (42.9) } \\
\text { No intervention: } 0(0.0) \\
\text { Total: } 4 \text { (44.4) }\end{array}$ & $\begin{array}{l}\text { Surgical: } 1 \text { (50.0) } \\
\text { Medical: } 1 \text { (14.3) } \\
\text { No intervention: } 0 \text { (0.0) } \\
\text { Total: } 2 \text { (22.2) }\end{array}$ \\
\hline $\begin{array}{l}\text { All glaucoma patients } \\
\text { Surgical: } 31 \\
\text { Medical: } 55 \\
\text { No intervention: } 4 \\
\text { Total: } 90\end{array}$ & $\begin{array}{l}\text { Surgical: } 25 \text { (80.6) } \\
\text { Medical: } 38 \text { (69.1) } \\
\text { No intervention: } 0(0.0) \\
\text { Total: } 90(70.0)\end{array}$ & $\begin{array}{l}\text { Surgical: } 4(12.9) \\
\text { Medical: } 15(27.3) \\
\text { No intervention: } 0 \text { (0.0) } \\
\text { Total: } 19 \text { (21.1) }\end{array}$ \\
\hline
\end{tabular}

* eye enucleated due to eye pain 
Table 5. Distribution of childhood glaucoma using CGRN classification compared to previous studies

\begin{tabular}{|c|c|c|c|c|c|c|c|c|}
\hline Study & $\begin{array}{l}\text { Babaran and } \\
\text { Florcruz } \\
\text { (2019) }\end{array}$ & $\begin{array}{l}\text { Aponte } \\
(2010)^{8}\end{array}$ & $\begin{array}{l}\text { Papadoupoulos } \\
(2007)^{7}\end{array}$ & $\begin{array}{l}\text { Senthil } \\
(2019)^{10}\end{array}$ & $\begin{array}{l}\text { Hoguet } \\
(2016)^{12}\end{array}$ & $\begin{array}{l}\text { Mokbel } \\
(2018)^{9}\end{array}$ & $\begin{array}{l}\text { Fung } \\
(2013)^{13}\end{array}$ & $\begin{array}{c}\text { Taylor } \\
(1999)^{14}\end{array}$ \\
\hline Location & $\begin{array}{l}\text { Philippine } \\
\text { General } \\
\text { Hospital }\end{array}$ & $\begin{array}{l}\text { Olmstead } \\
\text { County, } \\
\text { Minnesota }\end{array}$ & United Kingdom & South India & $\begin{array}{c}\text { Miami, Florida } \\
\text { USA }\end{array}$ & $\begin{array}{l}\text { Dakhelia, } \\
\text { Egypt }\end{array}$ & Dallas & Toronto \\
\hline Year & $2015-2017$ & $1965-2004$ & 2001-2002 & $2013-2014$ & -2013 & $2014-2017$ & 2005-2009 & 1974-1995 \\
\hline Study type & $\begin{array}{l}\text { Retrospective } \\
\text { Chart Review }\end{array}$ & $\begin{array}{l}\text { Retrospective } \\
\text { Chart Review }\end{array}$ & Prospective & Prospective & $\begin{array}{l}\text { Retrospective } \\
\text { Chart Review }\end{array}$ & $\begin{array}{l}\text { Retrospective } \\
\text { Chart Review }\end{array}$ & $\begin{array}{l}\text { Retrospective } \\
\text { Chart review }\end{array}$ & $\begin{array}{l}\text { Retrospective } \\
\text { Chart Review }\end{array}$ \\
\hline Coverage & $\begin{array}{c}\text { Single } \\
\text { Institution }\end{array}$ & $\begin{array}{c}\text { Population } \\
\text { based }\end{array}$ & $\begin{array}{c}\text { Population } \\
\text { based }\end{array}$ & $\begin{array}{c}\text { Single } \\
\text { institution }\end{array}$ & $\begin{array}{c}\text { Single } \\
\text { institution }\end{array}$ & $\begin{array}{c}\text { Single } \\
\text { institution }\end{array}$ & $\begin{array}{c}\text { Single } \\
\text { institution }\end{array}$ & $\begin{array}{c}\text { Single } \\
\text { institution }\end{array}$ \\
\hline Population Size & 77 & 30 & 99 & 275 & 205 & 207 & 239 & 306 \\
\hline Eyes & 104 & 45 & 142 & 449 & & 305 & 376 & 502 \\
\hline Bilateral & $50(64.9 \%)$ & $15(50 \%)$ & - & $174(63.3 \%)$ & $73(60 \%)$ & $98(47.3 \%)$ & - & $214(70.2 \%)$ \\
\hline Unilateral & 27 (35.1\%) & $15(50 \%)$ & - & $101(36.7 \%)$ & $49(40 \%)$ & 109 (52.7\%) & - & 92 (30.1\%) \\
\hline Male & 49 (63.6\%) & $16(53.3 \%)$ & - & - & $114(56 \%)$ & $132(64 \%)$ & $133(55.6 \%)$ & - \\
\hline Female & $28(36.4 \%)$ & $14(46.7 \%)$ & - & - & $91(44 \%)$ & $75(36 \%)$ & 106 (44.4\%) & - \\
\hline PCG & $12(15.6 \%)$ & $1(3.3 \%)$ & 45 (45.5\%) & 107 (38.9\%) & 39 (19\%) & 114 (55.1\%) & 46 (19.2\%) & $117(38.2 \%)$ \\
\hline JOAG & $4(5.2 \%)$ & $4(13.3 \%)$ & $2(2.0 \%)$ & 38 (13.8\%) & $9(4.4 \%)$ & $2(1 \%)$ & $10(8.4 \%)$ & $7(2.3 \%)$ \\
\hline $\begin{array}{l}\text { Acquired } \\
\text { Secondary } \\
\text { Glaucoma }\end{array}$ & $34(44.2 \%)$ & $19(63.3 \%)$ & $18(18.2 \%)$ & $44(16 \%)$ & $28(13.7 \%)$ & $61(29.5 \%)$ & 44 (15.9\%) & 35 (11.4\%) \\
\hline $\begin{array}{l}\text { Secondary } \\
\text { glaucoma, } \\
\text { non-acquired, } \\
\text { Systemic }\end{array}$ & 1 (1.3\%) & 4 (13.3\%) & 12 (12.1\%) & $16(5.8 \%)$ & $22(6.8 \%)$ & 4 (1.9\%) & 18 (7.5\%) & 36 (11.8\%) \\
\hline $\begin{array}{l}\text { Secondary } \\
\text { glaucoma } \\
\text { non-acquired, } \\
\text { non-systemic }\end{array}$ & $13(16.9 \%)$ & 2 (6.7\%) & $6(6.1 \%)$ & 48 (17.5\%) & $10(4.9 \%)$ & $11(5.3 \%)$ & $16(6.7 \%)$ & 49 (16.0\%) \\
\hline $\begin{array}{l}\text { Glaucoma after } \\
\text { cataract surgery }\end{array}$ & $6(7.8 \%)$ & - & - & 22 (8.0\%) & 22 (10.7\%) & $15(7.2 \%)$ & 30 (10.9\%) & 61 (19.9\%) \\
\hline $\begin{array}{l}\text { Glaucoma } \\
\text { suspect }\end{array}$ & 7 (9.1\%) & 24 (44.4\%) & - & - & 79 (38.5\%) & - & 75 (31.4\%) & - \\
\hline
\end{tabular}

is still at 0.9 . Visual acuity is unchanged from the initial recorded (central, unsteady, maintained). No perimetry testing was done. The patient was treated only medically with 2 medications.

\section{Glaucoma associated with non-acquired ocular conditions}

Four eyes underwent surgical interventions, 2 patients with ectopia lentis underwent intracapsular cataract extraction, and one patient with iris cyst underwent multiple surgical interventions: peripheral iridotomy, anterior chamber washout, and eventual enucleation. One patient with anterior segment dysgenesis had lens extraction and secondary lens implantation. Only one patient of the 13 had documented EUA. Nine of 16 eyes (56.3\%) achieved an IOP below $21 \mathrm{mmHg}$. Intraocular pressure change was not statistically significant from initial to the final follow-up at $26.5 \pm 13.9 \mathrm{mmHg}$ to $20.7 \pm 12.1 \mathrm{mmHg}(\mathrm{p}=0.23)$. Final visual acuity was the worst out of the 6 categories, where 7 of $16(43.8 \%)$ affected eyes had a visual acuity of less than 20/200. (Table 4)

\section{Glaucoma following cataract surgery}

Two of the 5 aphakic eyes underwent surgical intervention: one primary trabeculectomy and one primary glaucoma drainage device implantation. All 3 pseudophakic cases were managed medically. Two of 5 aphakic eyes (40\%) were uncontrolled on the final follow-up. Excluding patients with glaucoma suspect, initially, $70 \%$ of eyes included in the study had an intraocular pressure of $>21 \mathrm{mmHg}$ and on final follow up, only $21.1 \%$ of eyes had an intraocular pressure of $>21 \mathrm{mmHg}$. Surgical interventions led to a relative improvement in the ratio of eyes reaching IOP control of less than $21 \mathrm{mmHg}$ at $(87.1 \%)$ compared to eyes treated purely medically $(72.7 \%)$, with a significant decrease in mean IOP in eyes treated surgically vs. medically. Mean change in IOP was not statistically significant. (Table 4)

\section{Glaucoma suspect}

The 14 eyes had an average final noted IOP of $13.8 \pm 6.5$ $\mathrm{mmHg}$, with an average topical medication use of $0.5 \pm 0.5$. Documentation was done in 5 of the 7 patients: 1 patient underwent disc photo, automated visual field testing, and 
ocular coherence tomography. Four other patients underwent a disc photo. Cup disc ratio was noted at $0.63 \pm 0.22$ for the 14 eyes.

\section{DISCUSSION}

Childhood glaucoma is a heterogeneous group of disorders that lead to increased intraocular pressure and progressive visual loss. The CGRN Classification system was a tool already used in different regions to describe glaucoma. ${ }^{9} 12$ Applying the CGRN system in our patient population provides a way to compare the incidence of childhood glaucoma in other regions.

Philippine General Hospital is a tertiary referral center that receives patients from greater Metro Manila. Seventyseven (77) cases were identified during the study period and secondary glaucoma associated with acquired conditions consist $44.1 \%$ of the patient sample, followed by glaucoma from non-acquired non-systemic conditions (16.9\%) and PCG (15.6\%). This distribution of patients is similar to the study done by Aponte where the majority of patients were of acquired glaucoma (63.3\%). ${ }^{8}$ Other studies done in the United Kingdom, South India, Minnesota, USA Florida, USA, and Toronto, Canada had a distribution of $<20 \%$ for secondary glaucoma from acquired conditions. ${ }^{7,10,12-14}$ Other single institution-based studies, had higher recorded numbers of PCG consisting of at least 19\% in South India, Dahkelia, Egypt, and Beijing, China. ${ }^{7,9,10,20}$ Notably, in a populationbased study in the United Kingdom, Papadoupoulos et al. showed a higher prevalence of PCG in patients of SouthAsian (Pakistani) descent compared to western populations (2.46 incidence per 1000000). ${ }^{7}$ Similar to other studies, there is a male bias in our patient population (63.6\%) with a $68.8 \%$ male prevalence in primary congenital glaucoma and juvenile open-angle glaucoma and $64.2 \%$ male predominance in secondary glaucomas. The male predominance was also noted in populations with high consanguineous births such as in India even in Asian populations in the United Kingdom. ${ }^{7,9,10}$ Other single-center studies in the United States also reported a male predominance in childhood glaucoma (Table 5). ${ }^{12,13}$

The distribution of JOAG (5.2\%) is similar to other reports, having a presentation of $<20 \%$ in their respective patient populations (Table 5)..$^{6-8,10,11,15,16}$ The BIG multicenter eye study only recorded JOAG in $2 \%$ of its patient population. ${ }^{7}$ Onset of JOAG can span from 4 years to 40 years with a previously recorded mean age of diagnosis of 26.8 \pm 7.3 years as noted by Kwun in 2016. ${ }^{21}$

Acquired glaucoma secondary to trauma consisted of $21.5 \%$ of our patient population. This is similar to Tongren Hospital in China where trauma cases consisted of $13.4 \%$ of the patient population..$^{20}$ The glaucoma section of Philippine General Hospital is a tertiary center that accepts referrals from other sections and institutions as well as trauma referrals hence an increase in the incidence of trauma and other acquired conditions. Notably, there were three cases of acquired glaucoma secondary to malignancies: retinoblastoma, intraocular bleed from ALL, and 1 intracranial tumor. ${ }^{19}$

Secondary glaucoma from non-acquired, systemic conditions was only recorded in one case of Sturge-Weber syndrome (1.3\%). Other studies in Dallas, Minnesota, Florida, and Toronto, had a higher prevalence of glaucoma associated with systemic conditions, ranging from 6.8$13.3 \%$ prevalence. ${ }^{8,12-14}$ Other Asian populations had lower percentages of glaucoma associated with systemic conditions ranging from $1.9 \%$ to $5.8 \%{ }^{9,10,20}$

Secondary glaucoma associated with ocular conditions was seen in 16 eyes of 13 (16.3\%) patients. Patients were diagnosed below 6 years old in $8(61.5 \%)$ patients, with the most common diagnosis of anterior segment dysgenesis in $25 \%$ of the cases. Previous studies reported a range of $5.3 \%-17.5 \%{ }^{7,8,10}$ (Table 5)

Glaucoma associated with cataract surgery was seen in $7.7 \%$ of our patient population with half of those patients aphakic. Other studies have similar prevalence ranges from $7.2 \%$ to $10.9 \% .^{9}{ }^{910,12}$

Other studies recorded a higher number of patients with glaucoma suspects notably in Minnesota and Dallas, ranging from $31.4 \%-44.4 \%$ of the patient population. ${ }^{8,13}$ The lack of glaucoma suspects managed by the glaucoma service can be due to patients being managed in the general ophthalmology service. These patients may have been managed and diagnosed in primary care. Management and documentation may have been done in primary care hence most of the patients did not reach the records of the glaucoma service.

The most common reason for referral to the glaucoma service was documented elevated IOP in the pediatric patients seen in the general clinics or subspecialty clinics in $29.9 \%$ of the patients, with $60.8 \%$ of those eyes from acquired conditions (traumatic hyphema, blunt trauma), retinal surgery and malignancy. Elevated IOP was the reason for referral for $83.3 \%$ of glaucoma following cataract surgery as a referral from the pediatric ophthalmology service. Incidence of glaucoma in post-surgery patients is asymptomatic and not self-reported, which highlights the need for close monitoring. Trauma was the most common cause of secondary glaucoma associated with acquired conditions: (42.1\%) which is comparable to studies done in South India and Beijing, China. ${ }^{10,20}$

The majority of eyes in our patient population underwent purely medical intervention (71.1\%). Primary surgical intervention in the form of primary trabeculectomy or GDD implantation was done only in $24(26.6 \%)$ eyes. Surgical interventions were more common in previously reported studies, ranging from $43.0 \%$ in India, 84.6\% in Egypt, 94\% in the United Kingdom, and $93.7 \%$ in Dallas, USA. ${ }^{7,910,13}$ Trabeculectomy was the most common primary intervention (47.4\%). This is comparable to previous studies in the UK and 
the United States. ${ }^{7,13}$ Recently, Senthil reported combined trabeculectomy-trabeculectomy (CTT) as the primary surgical intervention in South India. ${ }^{10}$ In our institution, some difficulties for obtaining can include obtaining pediatric and anesthesiologic clearance before surgery.

The BIG study obtained a target of $\leq 21 \mathrm{mmHg}$ for control of IOP, with 94\% of eyes with PCG achieving that IOP target, in comparison, our study achieved the target in $80.7 \%$ (21 of 26 ) eyes on PCG and JOAG. (Table 4). Secondary glaucoma achieved similar levels of IOP control in our population: 51 of 64 (79.7\%) eyes achieved an IOP of $\leq 21 \mathrm{mmHg}$ while patients in the BIG study had control in $86 \%$ of eyes. ${ }^{7}$

\section{Limitations}

To our knowledge, this is the first study in the region that applied the CGRN classification system in documenting childhood glaucoma, however, there are several limitations to the study. This is a retrospective study hence there are incomplete data with documentation. Few eyes had documented refraction, corneal diameter, angle structure axial length, or documented optic disc parameters. EUA was only done in patients who underwent surgical interventions. Follow-up duration is variable with our data which makes it difficult to quantify progression and outcomes.

Also, this study had fewer documented glaucoma suspect patients compared to previous studies, since this study covered patients referred to the glaucoma service. ${ }^{10,12}$ Patients diagnosed in the primary ophthalmology services may not have been referred to the specialty clinics and may have been managed at the primary level.

\section{Recommendation}

The CGRN classification system allows for the comparison of prevalence and outcomes of childhood glaucoma in other populations. Recently an international registry was developed: Robison D. Harley, MD CGRN International Pediatric Glaucoma Registry, which allows for a prospective centralized collection of data over different populations and time-periods. ${ }^{5}$ Complete data collection particularly in refraction, corneal diameter, and optic nerve visualization is recommended in future cases with childhood glaucoma. One recommendation could be a standardized data sheet and follow-up form for childhood glaucoma which conforms with the International Pediatric Glaucoma Registry.

\section{CONCLUSION}

The CGRN classification system provided a concise method of classifying childhood glaucoma in our patient population. Secondary glaucoma associated with acquired conditions was the most prevalent (44.2\%) PCG consisted of $15.6 \%$ of the patient population. Trauma was the most prevalent cause of secondary acquired glaucoma. The male:female ratio is $1.75: 1$ and the patient population is $64.9 \%$ bilateral. Trabeculectomy was the primary surgical intervention in $22.2 \%$ of eyes, with $78.9 \%$ of eyes reaching an IOP control of $<21 \mathrm{mmHg}$ on final follow-up.

\section{Acknowledgment}

We thank Ms. Angelica Latorre for her guidance.

\section{Statement of Authorship}

Both authors participated in data collection, analysis and approved the final version submitted.

\section{Author Disclosure}

Both authors declare no conflicts of interest.

\section{Funding Source}

This study was self-funded by the authors.

\section{REFERENCES}

1. Singh P, Kumar Y, Tyagi M, Kuldeep K, Das Sharma P. Childhood glaucoma: an overview. Open J Ophthalmol. 2012; 2(3):71-7. doi:10.4236/ojoph.2012.23015

2. Beck A, Chang TP, Freedman S. Childhood Glaucoma: Definition, Classification, Differential Diagnosis. In: Childhood Glaucoma. World Glaucoma Association Consensus. Amsterdam, The Netherlands: Kugler Publications; 2013. pp.3-10.

3. Hoskins HD, Shaffer RN, Hetherington J. Anatomical Classification of the Developmental Glaucomas. Arch Ophthalmol. 1984 Sep; 102(9):1331-6. doi:10.1001/archopht.1984.01040031081030.

4. Yeung HH, Walton DS. Clinical classification of childhood glaucomas. Arch Ophthalmol. 2010 Jun; 128(6):680-4. doi:10.1001/ archophthalmol.2010.96

5. Thau A, Lloyd M, Freedman S, Beck A, Grajewski A, Levin AV. New classification system for pediatric glaucoma: implications for clinical care and a research registry. Curr Opin Ophthalmol. 2018 Sep; 29(5):385-94. doi:10.1097/ICU.0000000000000516.

6. Gogate $\mathrm{P}$, Gilbert C, Zin A. Severe visual Impairment and blindness in infants: causes and opportunities for control. Middle East Afr J Ophthalmol. 2011 Apr; 18(2):109-14. doi:10.4103/0974-9233.80698

7. Papadopoulos M, Cable N, Rahi J, Khaw PT. The British Infantile and Childhood Glaucoma (BIG) Eye Study. Invest Opthalmol Vis Sci. 2007 Sep; 48(9):4100-6. doi:10.1167/iovs.06-1350

8. Aponte EP, Diehl N, Mohney BG. Incidence and clinical characteristics of childhood glaucoma: a population-based study. Arch Ophthalmol. 2010 Apr; 128(4):478-82. doi: 10.1001/ archophthalmol.2010.41.

9. Mokbel TH, Hefney EME, Hagras SM, ALNagdy AA, Badawi AE, Kasem MA, et al. Childhood glaucoma profile in Dakahelia, Egypt: a retrospective study. Int J Ophthalmol. 2018 Apr; 11(4): 674-80. doi:10.18240/ijo.2018.04.23

10. Senthil S, Badakere S, Ganesh J, Krishnamurthy R, Dikshit S, Choudhari N, et al. Profile of childhood glaucoma at a tertiary center in South India. Indian J Ophthalmol. 2019 Mar; 67(3): 358-65. doi:10.4103/ijo.IJO_786_18

11. Fang Y, Long Q, Guo W, Sun X. Profile of pediatric glaucoma patients in Shanghai Eye, Ear, Nose and Throat Hospital. Chin Med J (Engl). 2014;127(8):1429-33. doi:10.3760/cma.j.issn.0366-6999.20133083

12. Hoguet A, Grajewski A, Hodapp E, Chang TCP. A retrospective survey of childhood glaucoma prevalence according to Childhood Glaucoma Research Network classification. Indian J Ophthalmol. 2016 Feb; 64(2):118-23. doi:10.4103/0301-4738.179716

13. Fung DS, Roensch MA, Kooner KS, Cavanagh HD, Whitson JT. Epidemiology and characteristics of childhood glaucoma: results 
from the Dallas Glaucoma Registry. Clin Ophthalmol. 2013; 7: 1739-46. doi:10.2147/OPTH.S45480

14. Taylor RH, Ainsworth JR, Evans AR, Levin AV. The epidemiology of pediatric glaucoma: The Toronto experience. J AAPOS. 1999 Oct; 3(5):308-15. doi:10.1016/S1091-8531(99)70028-5

15. FlorCruz NV, Joaquin-Quino R, Silva PAS, Khu PM. Profile of glaucoma cases seen at a tertiary referral hospital. Philipp J Ophthalmol. 2005 Oct-Dec; 30(4):161-5.

16. Martinez JM, Hosaka MAB. Clinical profile and demographics of glaucoma patients managed in a Philippine tertiary hospital. Philipp J Ophthalmol. 2015 Jul-Dec; 40(2):81-7.

17. Philippine National Health Research Ethics Board. Section 17: Waiver of Informed Consent. In: National Ethical Guidelines for Health and Health-Related Research 2017. 2017th ed. Department of Science and Technology - Philippine Council for Health Research and Development; 2018. pp.15-16.
18. Dean A, Sullivan K, Soe M. OpenEpi: Open Source Epidemiologic Statistics for Public Health Version 3.01. Two-sample independent t-TestOpenEpi: Open Source Epidemiologic Statistics for Public Health Version 3.01 [Internet]. [cited 2019 Aug 15]. Available from: https://www.openepi.com/Mean/t_testMean.htm.

19. Sosuan GMN, Eleazar-Verde JT, Mercado GJV, Arroyo MH. Retinoblastoma presenting as haemorrhagic choroidal detachment in a 10-year-old girl. BMJ Case Rep. 2018 Oct; 2018:bcr2018226149. doi:10.1136/bcr-2018-226149

20. Qiao CY, Wang LH, Tang X, Wang T, Yang DY, Wang NL. Epidemiology of hospitalized pediatric glaucoma patients in Beijing Tongren Hospital. Chin Med J (Engl). 2009 May; 122(10):1162-6.

21. Kwun Y, Lee EJ, Han JC, Kee C. Clinical characteristics of juvenileonset open angle glaucoma. Korean J Ophthalmol. 2016 Apr; 30(2): 127-33. doi:10.3341/kjo.2016.30.2.127

\section{The Acta Medica Philippina is now accepting limited advertising for its front and back cover (colored), as well as for available spaces in some of its pages, as appropriate. For inquiries and submission of proposals, please email us at actamedicaphilippina.upm@up.edu.ph}

